\title{
Using Audio and Interference as Locative Art
}

\author{
Jen Southern, Sam Thulin, \\ Adrian Gradinar \\ LICA \\ Lancaster University \\ \{j.a.southern, s.thulin, \\ a.gradinar\}@lancaster.ac.uk
}

\author{
Mark Lochrie, Paul Egglestone \\ Media Innovation Studio \\ University of Central Lancashire \\ \{mlochrie, \\ pegglestone\}@uclan.ac.uk
}

\author{
Charles Quick, Elaine Speight \\ In Certain Places \\ University of Central Lancashire \\ \{cquick,espeight\}@uclan.ac.uk
}

\begin{abstract}
This research presents initial work that brings together artists, designers, technologists and the community of content creators to describe the events of World War I through the voices of families and soldiers. These stories, that would have been otherwise lost, are restored and narrated in modern day, and finally distributed through new locative audio experiences. Homing is a locativebased audio navigation experience designed to encourage visitors to explore these stories by visiting the Harris Museum Roll of Honour and War Memorial. The project brings to life the museum and the Cenotaph to unite and bridge the physical gap between two artefacts to tell and disrupt a broader story.
\end{abstract}

Homing. GPS. Beacons. Mobile. Audio. Locative. Media. Stories.

\section{INTRODUCTION AND BACKGROUND}

Nowadays, it is relatively common, even for smaller museums, to enhance the experience of their visitors with audio. Strolling away through the corridors of the museum, a minimalistic carry-on system, similar to a tape recorder, delivers different audio descriptions at a press of a button. For more than two decades, researchers have looked at further enhancing the museum experience by making use of the 'perceived' physical location of the user, tide to the technological advances of that time period. Infrared technologies (IR) augmenting physical spaces 'tell the computer where the viewer is" and allow the control of the delivery of audio tracks (Benderson, 1995); audio beacons shaped by IR and barcode enabled systems that supply webpage base information to museum visitors to "better plan their visits" (Spasojevic, 2001); or, more recently, beacon positioning systems coupled with mobile phone based interactions to provide audio, video and text-based content when in the vicinity of an exhibit (He, 2015) are just few approaches employed to deliver richer and more meaningful experiences. The beacon technology, based around Bluetooth Low Energy (BLE), seems to be favoured for many indoor applications such as accessibility or navigation for; retail, museums and transport. Although beacons are not novel, Parry et al. (Parry, 2009) extensively investigated narrative strategies for scalable locative audio dramas. Their findings of content, models and modes of interaction were also identified by Reid et al. (Reid, 2005) in their analysis of Location Based
Audio (LBA) dramas which resulted in an increase in enjoyment, immersion and history knowledge for this particular genre.

'Homing' was commissioned by 'In Certain Places' (ICP) in partnership with Preston City Council (PCC), as part of the Heritage Lottery funded project 'Preston Remembers'. The art work was commissioned to bridge the physical gap between the inside exploration of the Harris Museum and the Preston Cenotaph, a close-by outside monument dedicated to the soldiers from Preston who died during the World War I and II, and more recently re-dedicated to all soldiers from Preston who have died since 1914. Homing is an examination of how artists can contribute to the form and functions of a place, by exploring new approaches to art, culture and urban development. Working with location and contemporary sound technologies allows the project to generate new understandings of the urban environment, enabling new ideas to be tested in the city's public spaces whilst forming collaborations between artists, institutions, and communities. The work builds on a history of locative audio art works that use GPS technologies to place dynamically changing audio into specific sites, producing a temporal layering between the participants' experience and sounds associated with the history of the site and locally produced fiction (Knowlton, 2002), textural sound that changes as participants movements create layers of noise within an audio landscape (Symons, 2007; Behrendt, 2016), or sounds which are geolocated but also move with the tide, encouraging participants to experience a space in 
flux through playful wandering through the physical location and the soundscape (Rueb, 2004).

Homing uses modern communication technologies to make connections between distant locations: the battlefields of WWI and Preston's Roll of Honour and War Memorial. In a walk from The Roll of Honour to The War Memorial, participants will experience live sound from France and stories from the Front. These stories can never be heard in full, as interference from sonified GPS, the targeting technology of modern warfare, disrupts the stories of people on the ground. The current research looks at how the beacon technology could be used within both the locative art and museum landscape to encourage visitors to move freely between indoor and outdoor spaces by creating a platform which places emphasis on using audio and interference as a mechanism for navigation. Audio is used as the primary mechanism for navigation and interference becomes this disruptive narrative throughout the journey.

\section{HOMING}

Homing is a new art work based on the Infantry museum archives of letters to and from Preston soldiers serving in WWI. These letters are testament to the attempts of soldiers and their loved ones to keep in touch despite the distances and horrors of war. These distances were not only physical, as they were also experienced in the mind; the longer the war continued the greater the distance in life experience between soldiers and those at home. Each letter represents an attempt to bridge that gap, and as much as is said, more is unsayable or left unsaid. Homing is about different modes of communication in WWI and contemporary war. It contrasts current technologies of war that emphasise accuracy (how GPS is used to home a missile, and the affects this has when inaccurate), immediacy and removal of the body from warfare, with the harrowing battles fought in the trenches of WWI expressed in letters to home. We use these traits seen in modern warfare as a design mechanism within the experience proposed. For example, the views from the ground are disrupted by a sonified GPS signal which, instead of promising accuracy, prevents a complete story from being heard. This intensifies at the memorial where a 'fog of war' and grief takes over from individual voices. At the Roll of Honour, a live audio channel is open to the site of a battlefield in the Somme, making a connection to the physical site of the battle and where some of the letters were written. The live audio and the GPS fog are forms of absence, and suggest that a connection to peoples' lives is impossible through a memorial, but is available in the everyday activity of the flag market. The work is formed by two parts: a live audio stream, from the Somme, acting as no man's land, which can be heard near the Roll of Honour (indoors) making a live connection to the place where so many died; and a locative audio piece in the flag market (the area facing the memorial and between the museum). Participants can join the experience in one of two ways; either through the bespoke museum object, a small, lightweight piece with headphones provided by the Harris Museum, or via a mobile device (as longevity and saleability are essential requirements to the project). Visitors walking around the flag market will hear letters from the infantry museum archive, read by local voices. The audio tracks are however obstructed in parts by sounds generated from GPS data captured via post, person or pigeon, limiting the full comprehension of the story. For example, during $W W I$, alongside the postal system pigeons were extensively used as 'homing pigeons' to delivery messages; similarly acquired GPS data will be used to 'disrupt' the listening narrative.

As participants navigate their way from inside the museum to the war memorial they hear short sentences first. These random samples, designed to be intriguing, lead the audience into the work. The closer visitors get to the memorial, the greater the auditory interference becomes, potentially creating an emotional intensity that isolates the participant from the rest of the square. Visitors will never hear both sides of the conversation or a whole letter in full; without a full story they hear fragments, a stilted marriage proposal, an enquiry about health, a thank you for kippers sent through the post, a description of conditions in the trenches. The beacons are used to form pockets within zones whereby themed stories are associated. A story is played randomly within the theme and, if a visitor navigates to another zone, further or closer to the war memorial, a new story is played. Through audio only, visitors will understand that they are moving to a new theme as a static "tuning in" noise will mark the boundary between different narratives, similar to tuning into an analogue radio station.

\section{CONCLUSION}

This paper introduces the initial design and rational of the Homing project. The project will be revealed in May 2016 (Harris, 2016) to the wider public, where guests can take part in the experience. A study will be conducted around using location as a means of revealing stories. The impact of the project will be determined by examining the footfall at the museum before and after the delivery of the project. Qualitative data will be captured regarding the experience and the design of the project. By developing the platform with off the shelf technologies, we are moving towards opening the project up as a special/locative audio standard allowing interested parties to download the source 
code or the schematics for the objects and facilitate the build of own devices and the implementation of own audio projects.

\section{REFERENCES}

Bederson, B. (1995). Audio augmented reality: a prototype automated tour guide. In Conference Companion on Human Factors in Computing Systems (CHI '95), I. Katz, R. Mack, and L. Marks (Eds.). ACM, New York, NY, USA, 210-211. DOI=http://dx.doi.org/10.1145/223355.223526

Behrendt, F. (2016). "Creative Sonification of Mobility and Sonic Interaction with Urban Space: An Ethnographic Case Study of a GPS Sound Walk." Oxford Handbooks Online. 2014-07-01. Oxford University Press. Date of access 5 Mar. 2016.

Harris Museum (May, 2016), http://www. harrismuseum.org.uk/exhibitions/1050-homingby-jen-southern-and-sam-thulin (visited on 06 June 2016).
He, Z., Cui, B., Zhou, W., \& Yokoi, S. (2015, July). A proposal of interaction system between visitor and collection in museum hall by iBeacon. In Computer Science \& Education (ICCSE), 2015 10th International Conference on (pp. 427-430). IEEE.

Knowlton, G., Spellman, N. \& Hight, J. (2002) 34 North 118 West. LA Freewaves Festival, LA.

Parry, N, et al. "Exploring Narrative Strategies for Scalable Locative Audio Drama."

Spasojevic, M., \& Kindberg, T. (2001). A study of an augmented museum experience. Hewlett Packard internal technical report.

Reid, J., Geelhoed, E., Hull, R., Cater, K. and Clayton, B., 2005, April. Parallel worlds: immersion in location-based experiences. In $\mathrm{CHI}$ '05 extended abstracts on Human factors in computing systems (pp. 1733-1736). ACM.

Rueb, T., 2004. Drift. Teri Rueb.

Symons, S. (2007) Aura, Enter Festival, Cambridge. 25-29April. 